\title{
Characterization of Aluminum Doped Lithium-Manganese Rich Composites for Higher Rate Lithium-Ion Cathodes
}

\author{
M. Iftekhar, ${ }^{a}$ N. E. Drewett, ${ }^{b}$ A. R. Armstrong, ${ }^{c}$ D. Hesp, ${ }^{b}$ F. Braga, ${ }^{b}$ S. Ahmed, ${ }^{a}$ \\ and L. J. Hardwick ${ }^{b, *, z}$ \\ ${ }^{a}$ Department of Chemistry, Quaid-i-Azam University, Islamabad 45320, Pakistan \\ ${ }^{b}$ Stephenson Institute for Renewable Energy, University of Liverpool, Liverpool L69 7ZF, United Kingdom \\ ${ }^{c}$ School of Chemistry, University of St Andrews, St. Andrews KY16 9ST, United Kingdom
}

\begin{abstract}
The effect of synthesis method and aluminum doping on layered lithium-manganese rich, mixed metal oxides is presented. Coprecipitation and sol-gel synthesized lithium-manganese rich composite materials revealed differences in capacity and cycle life, which appears from X-ray photoelectron spectra to be strongly related to the particles' surface reactivity. Small amounts of aluminum doping to the sol-gel material were shown to improve the rate capability and cyclability, in addition to decreasing voltage fade, as shown by differential capacity plots. The electrochemistry of an aluminum doped material was revealed to be highly dependent on

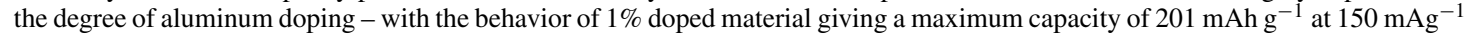
and a capacity retention of $88 \%$ after 200 cycles.

(C) The Author(s) 2014. Published by ECS. This is an open access article distributed under the terms of the Creative Commons Attribution 4.0 License (CC BY, http://creativecommons.org/licenses/by/4.0/), which permits unrestricted reuse of the work in any medium, provided the original work is properly cited. [DOI: 10.1149/2.0441414jes] All rights reserved.
\end{abstract}

Manuscript submitted July 18, 2014; revised manuscript received September 22, 2014. Published October 6, 2014. This was Paper 203 presented at the Orlando, Florida, Meeting of the Society, May 11-15, 2014.

The increasing energy consumption of modern societies has created a considerable demand for better approaches to not only the production and management of energy, but also its storage. Due to their high energy density and good specific energies lithium-ion batteries are attractive candidates for use in many applications such as portable devices, though there is considerable impetus for further improvement.

One potentially attractive family of cathode materials are layered lithium-manganese rich, mixed metal oxides (LMR-MMO materials), of the form $x \mathrm{Li}_{2} \mathrm{MnO}_{3}:(1-x) \mathrm{LiMO}_{2}$ (where $0<x<1$, and $\mathrm{M}$ represents transition metals such as cobalt, manganese and/or nickel). Their high capacities (at low cycling rates in excess of $220 \mathrm{mAh} \mathrm{g}^{-1}$ at room temperature and $300 \mathrm{mAh} \mathrm{g}^{-1}$ at $60^{\circ} \mathrm{C}$ ) have generated considerable interest. ${ }^{1-6}$ However, there are still significant challenges to overcome - chiefly the material exhibits power loss due to voltage fade on cycling. ${ }^{1,7,8}$ Furthermore, whilst properties such as capacity and cyclability are self-evidently of considerable importance, many applications require rapid access to stored energy and fast recharge times. Consequently, developing materials capable of operating at high rates is potentially quite significant.

From previous studies it is clear that the electrochemical and physical properties vary depending on the material's constituent elements, stoichiometry and method of synthesis. ${ }^{1-16}$ Given the importance of both the particle bulk and the surface to the behavior of these materials, ${ }^{17,18}$ understanding in what way the synthetic route affects these properties is of considerable importance - particularly if careful choice and optimisation of synthetic route may mitigate voltage fade.

Another possible approach to decreasing voltage fade and improving rate capability would be to dope the lithium-manganese rich material. While investigations into using chromium ${ }^{19,20}$ and ruthenium ${ }^{21}$ have been carried out, one potentially particularly attractive dopant is comparatively inexpensive aluminum. A computational study ${ }^{22}$ has suggested that a small degree of aluminum doping should have a stabilizing effect on the structure, resulting in a decrease in voltage fade. In addition, aluminum doping has been shown to improve the thermal stability of lithium-manganese rich composites at low cycling rates, though this improvement is sometimes accompanied by a corresponding decrease in capacity. ${ }^{23,24}$ Furthermore, it has recently been demonstrated that doping the manganese component with 0.02 aluminum improves the rate capability of $\mathrm{Li}_{1.2} \mathrm{Mn}_{0.54} \mathrm{Ni}_{0.13} \mathrm{Co}_{0.13} \mathrm{O}_{2}$, with the improvement being ascribed to aluminum doping increasing the $c$ lattice parameter, and thus enhancing the kinetics of $\mathrm{Li}^{+}$

\footnotetext{
*Electrochemical Society Active Member.
}

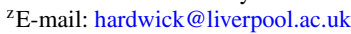

intercalation/deintercalation. ${ }^{25}$ However, a decrease in the capacity with respect to the parent material at low rates was again recorded.

Despite its significance, the effect of the degree of aluminum doping on high rate performance, cycling and voltage fade has yet to be fully considered. Moreover, whilst most studies are carried out at rates of $\sim 22 \mathrm{mAg}^{-1}$, here investigations were carried out at the much higher rate of $150 \mathrm{mAg}^{-1}$. We present here the differences in the electrochemistry between lithium-manganese rich metal oxides with the same stoichiometry, but synthesized using two different commonly used techniques, and the higher rate cycling of aluminum doped materials, and the effect of aluminum doping on capacity, cyclability and voltage fade.

\section{Experimental}

Synthetic method-Co-precipitation synthesized $\mathrm{Li}_{1.16} \mathrm{Ni}_{0.167} \mathrm{Mn}_{0.50} \mathrm{Co}_{0.167} \mathrm{O}_{2}$ was prepared by adding dropwise stoichiometric amounts of lithium, manganese, nickel and cobalt nitrates to a lithium hydroxide solution, with ammonia solution (35\% by weight) added to maintain a $p \mathrm{H}$ of 11 . The precipitate was washed with de-ionized water to remove the residual $\mathrm{LiOH}$, followed by calcining the oven-dried hydroxides with a stoichiometric amount (1.03 $\mathrm{Li}$ in the starting composition) of lithium hydroxide hydrate ( $\mathrm{LiOH} . \mathrm{H}_{2} \mathrm{O}$ ) for $500{ }^{\circ} \mathrm{C}$ for $4 \mathrm{~h}$, followed by a second calcination at $900{ }^{\circ} \mathrm{C}$ for $12 \mathrm{~h}$.

Sol-gel synthesized $\mathrm{Li}_{1.16} \mathrm{Ni}_{0.167} \mathrm{Mn}_{0.50-x} \mathrm{Al}_{x} \mathrm{Co}_{0.167} \mathrm{O}_{2}$ materials were prepared by adding appropriate stoichiometric ratios of lithium, manganese, nickel cobalt and aluminum nitrates to solutions of ethylene glycol and citric acid (1:4) in water, which were then heated to $90^{\circ} \mathrm{C}$ to form gels that were calcined at $250^{\circ} \mathrm{C}$ to form fine powders. These were then ground, pelletised and heated at $480^{\circ} \mathrm{C}$ for $4 \mathrm{~h}$, followed by a second calcination at $850^{\circ} \mathrm{C}$ for $10 \mathrm{~h}$.

Characterization.- Powder X-ray diffraction patterns were collected on a Stoe STADI/P diffractometer operating in transmission mode with $\mathrm{FeK} \alpha_{1}$ radiation ( $\alpha=1.936 \AA$ ) to eliminate manganese fluorescence. SEM and EDX images were collected on a JEOL 6610 scanning electron microscope operating at an accelerating voltage of $20.0 \mathrm{keV}$ fitted with EDX analysis equipment (Oxford Instruments INCAx-act X-ray detector). Raman spectra were recorded with a Raman microscope (Renishaw inVia), using a $532 \mathrm{~nm}$ wavelength laser focused through an inverted microscope (Leica), via a 50x objective (Leica).

X-ray photoelectron spectroscopy (XPS) experiments were performed in a standard ultrahigh vacuum surface science chamber 
consisting of a Scienta SES200 electron energy analyzer (angle integrating $\pm 10^{\circ}$ ) and a PSP vacuum dual anode X-ray source. The base pressure of the system was less than $1 \times 10^{-9}$ mbar, with hydrogen as the main residual gas in the chamber. The XPS measurements were carried out with a Mg K-alpha source $(1253.6 \mathrm{eV})$. The spectrometer was calibrated using Au 4f7/2 at $83.9 \mathrm{eV}$.

Surface area measurements were conducted using a Quantachrome NOVA 4200e Volumetric Gas Sorption Analyzer, employing high purity Nitrogen (99.9995) at 77.35 K. Approximately $400 \mathrm{mg}$ of each of the powders were degassed overnight at $350^{\circ} \mathrm{C}$ to $10^{-3} \mathrm{mbar}$ dynamic vacuum. The surface area of the powders were calculated via the multipoint Brunauer-Emmett-Teller (BET) analysis of the isotherm using five data points with relative pressures ranging from 0.1 to 0.3 .

To evaluate the performance of the lithium-manganese rich mixed metal oxides, composite electrodes were fabricated by casting a mixture (active material: Super C carbon: poly(vinylidene fluoridehexafluoropropylene) co-polymeric binder (Kynarflex, Arkema) in a ratio of 76:12:12\% by weight) onto an aluminum foil current collector. Coin cells (CR2025) were assembled in an argon-filled glove box (Innovative Technology, $\mathrm{O}_{2}, \mathrm{H}_{2} \mathrm{O}<1 \mathrm{ppm}$ ) using these composite electrodes, a glass fiber separator (Whatman) impregnated with $1 \mathrm{M}$ lithium hexafluorophosphate in 1:1 w/w ethylene carbonate: dimethyl carbonate (BASF) and a lithium metal counter electrode.

Electrochemical characterization of electrode cyclability was carried out at $30^{\circ} \mathrm{C}$ (Maccor Series 4200 battery cycler). EIS (SP 150, Biologic) measurements were obtained between $100 \mathrm{kHz}$ and $1 \mathrm{mHz}$, with a $3 \mathrm{mV}$ root mean squared AC signal. Cyclic voltammograms (SP 150, Biologic) were obtained at a scan rate of $0.1 \mathrm{mVs}^{-1}$.

After undergoing electrochemical measurements, the cells were disassembled inside an argon-filled glove box, the composite cathodes reclaimed and washed twice with dry dimethyl carbonate (Aldrich) for ex situ characterization of the cycled material.

\section{Results and Discussion}

Material characterization.- Powder X-ray diffraction (PXRD) patterns of the co-precipitation (CP) and sol-gel (SG) synthesized lithium-manganese rich, nickel manganese cobalt oxide (LMR NMC) materials are shown in Figure 1.

The PXRD patterns demonstrate that the materials have good crystallinity, with strong diffraction peaks that can be assigned to a unit cell with $\mathrm{R} \overline{\mathrm{3}} \mathrm{m}$ symmetry and weaker peaks at approximately $26^{\circ}$ characteristic of the $\mathrm{Li}_{2} \mathrm{MnO}_{3}$ type integrated phase with $C 2 / m$ symmetry. ${ }^{12,22,26}$ $\mathrm{No} \gamma-\mathrm{LiAlO}_{2}$ or $\mathrm{Al}_{2} \mathrm{O}_{3}$ peaks were detected, showing that the material

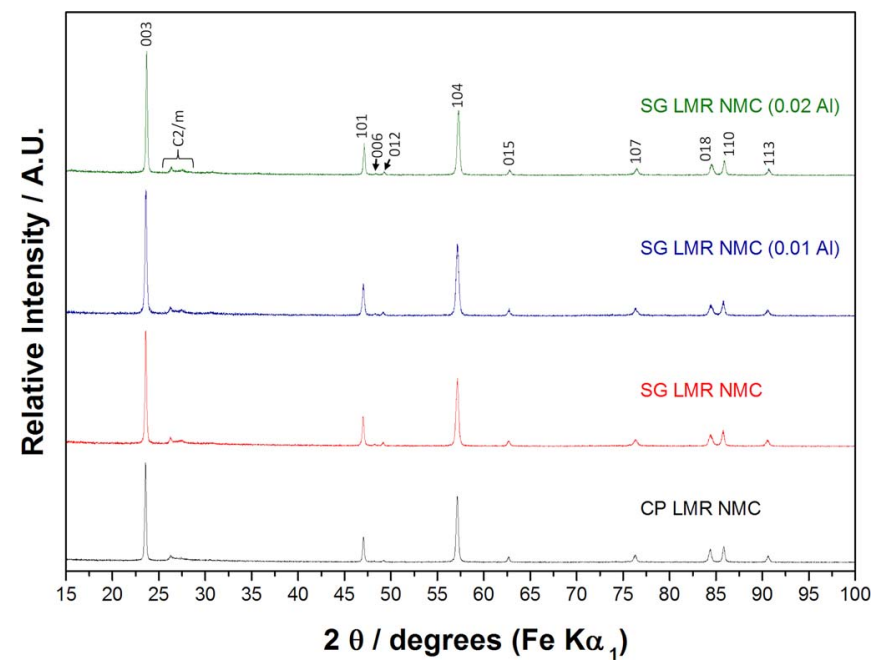

Figure 1. PXRD patterns for co-precipitation, sol-gel, sol-gel (0.01 Al doped) and sol-gel (0.02 Al doped) lithium-manganese rich nickel manganese cobalt oxides.

\section{Table I. Variation of the a and c lattice parameters.}

\begin{tabular}{lll} 
Sample & $\mathrm{a} / \AA$ & $\mathrm{c} / \AA$ \\
\hline CP LMR NMC & $2.8443(6)$ & $14.230(3)$ \\
SG LMR NMC & $2.8476(9)$ & $14.214(5)$ \\
SG LMR NMC (Al 0.01) & $2.8481(9)$ & $14.212(5)$ \\
SG LMR NMC (Al 0.02) & $2.8442(9)$ & $14.204(5)$
\end{tabular}
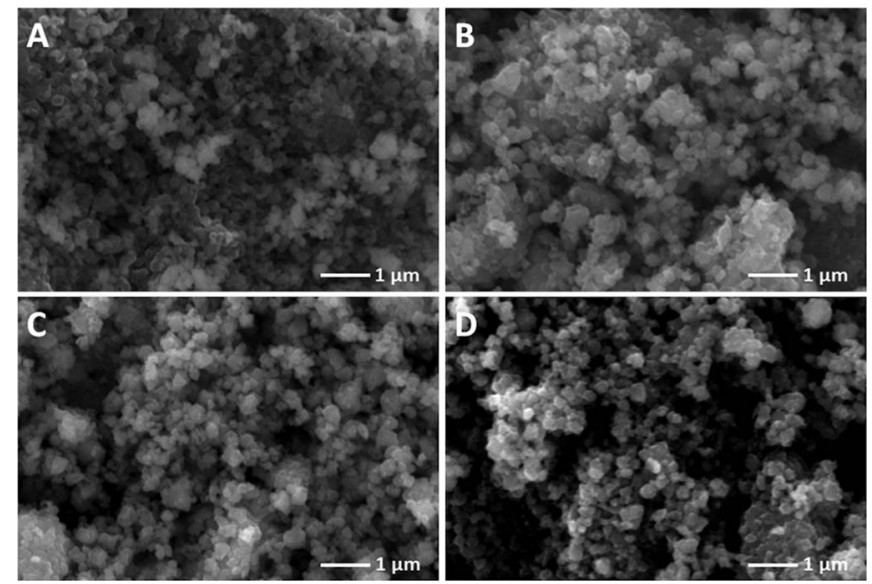

Figure 2. SEM images for A) co-precipitation; B) sol-gel C) sol-gel (0.01 $\mathrm{Al}$ doped) and $\mathrm{D})$ sol-gel (0.02 Al doped) lithium-manganese rich nickel manganese cobalt oxides.

was phase pure. The average particle size was calculated to be $\sim 50$ $\mathrm{nm}$. The lattice parameters (Table I) are in good agreement with the literature for both the undoped and the doped materials, ${ }^{24}$ suggesting that the aluminum has indeed been incorporated into the structure.

Scanning electron microscopy (SEM) images are presented in Figure 2, which indicate that all the synthesized materials consist of individual particles, with a narrow size distribution in the range of approximately 0.1 to $0.5 \mu \mathrm{m}$, fused together to form disordered agglomerates. Given the similarity between these materials it can be anticipated that particle size is unlikely to be responsible for any observed differences in the electrochemical performances of these materials.

From energy-dispersive X-ray spectroscopy (EDX) mapping of the CP and SG LMR NMC materials it was determined that both materials appear to have a relatively homogeneous distribution of elements throughout, though from the EDX data shown in Table II both the CP

\begin{tabular}{|c|c|c|c|c|}
\hline \multicolumn{5}{|c|}{ Table II. EDX data Li-Rich compounds. } \\
\hline & Nickel & Manganese & Cobalt & \\
\hline Average & 2.943 & 52.133 & 10.360 & \\
\hline Average ratio & 0.045 & 0.797 & 0.158 & \\
\hline Target & 0.167 & 0.667 & 0.167 & \\
\hline \multicolumn{5}{|c|}{ SG LMR NMC } \\
\hline & Nickel & Manganese & Cobalt & \\
\hline Average & 10.094 & 44.724 & 9.672 & \\
\hline Average ratio & 0.157 & 0.694 & 0.150 & \\
\hline Target & 0.167 & 0.667 & 0.167 & \\
\hline \multicolumn{5}{|c|}{ SG LMR NMC (0.01 Al) } \\
\hline & Nickel & Manganese & Cobalt & $\mathrm{Al}$ \\
\hline Average & 9.653 & 39.935 & 9.970 & 0.368 \\
\hline Average ratio & 0.161 & 0.666 & 0.166 & 0.006 \\
\hline Target & 0.167 & 0.657 & 0.167 & 0.010 \\
\hline \multicolumn{5}{|c|}{ SG LMR NMC (0.02 Al) } \\
\hline & Nickel & Manganese & Cobalt & $\mathrm{Al}$ \\
\hline Average & 10.183 & 39.64 & 9.853 & 0.470 \\
\hline Average ratio & 0.169 & 0.659 & 0.164 & 0.008 \\
\hline Target & 0.167 & 0.647 & 0.167 & 0.020 \\
\hline
\end{tabular}



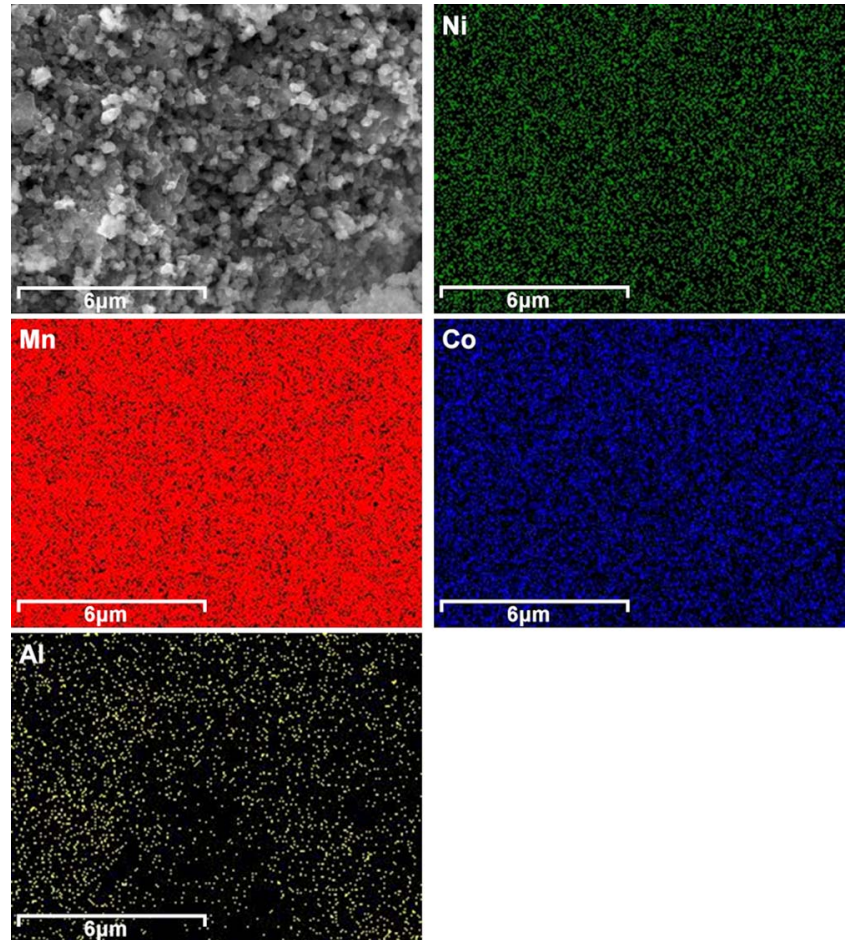

Figure 3. EDAX elemental maps of sol-gel lithium-manganese rich nickel manganese cobalt oxide ( $0.01 \mathrm{Al}$ doped)

and SG LMR NMC materials appear to be slightly manganese rich compared to the target stoichiometry. Furthermore, the CP LMR NMC is particularly nickel poor - a phenomenon which has previously been observed for other co-precipitation synthesized lithium-manganese rich materials. ${ }^{24}$ This could result from the fact that the $\mathrm{CP}$ synthetic
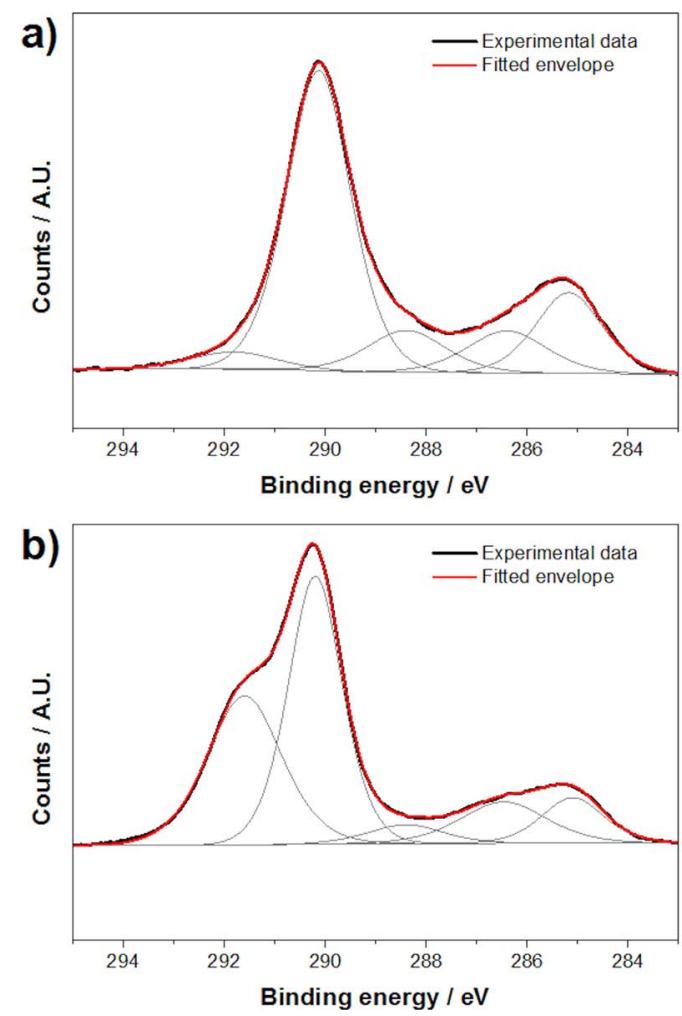

route requires very precise $p \mathrm{H}$ control, so that all constituent elements precipitate out homogenously. Therefore any minor variations during the dropwise addition stage results in inhomogeneity of transition metal ratio and distribution in the synthesized particles.

EDX maps of the 0.01 and 0.02 aluminum doped SG LMR NMC materials showed that the distribution of nickel, manganese and cobalt is homogenous throughout and that, whilst there is some apparent variation, there is a relatively even dispersal of aluminum (a typical EDX map is presented in Figure 3). From the EDX data in Table II it can be seen that not only are the materials again slightly manganese rich compared to the target stoichiometry, but also that they are aluminum poor compared to the target stoichiometry.

In order to investigate the differences between the CP and SG synthetic routes in more detail, the syntheses were repeated under a pure oxygen atmosphere. The CP and SG LMR NMC materials were then analyzed using XPS before and after 1 week of exposure to atmosphere. The carbon 1s spectra are shown in Figure 4. For the as entered SG sample, the Carbon 1s spectrum is dominated by the adventitious carbon $(285 \mathrm{eV})$ which is far stronger than the carbonate species (290.2 eV). By comparison the as entered CP sample is dominated by the carbonate species. Both samples also show $\mathrm{C}-\mathrm{O}(286.5 \mathrm{eV})$ and $\mathrm{C}=\mathrm{O}(288.4 \mathrm{eV})$. During the transfer of material into the XPS vacuum chamber there is a brief period (c.a. 1 minute) where the sample is exposed to atmosphere, and it is believed that these species were deposited during that time. Upon exposure to atmosphere for 1 week, the SG sample remains relatively unchanged. The CP sample, however, shows signs of aging, developing a feature at $291.6 \mathrm{eV}$ which belongs to a carbon with a higher oxidation state. ${ }^{27}$ It has previously been shown that lithium metal oxide materials react in air to form a carbonate-based film. ${ }^{28,29}$ Given that the degree of instability of a material's surface is closely linked to the speed of formation and thickness of carbonate-based film, it would seem reasonable to suggest that the rapid formation observed for the $\mathrm{CP}$ material is indicative of a greater degree of surface instability. To ensure that any observations were not a result of differences in surface area, BET measurements
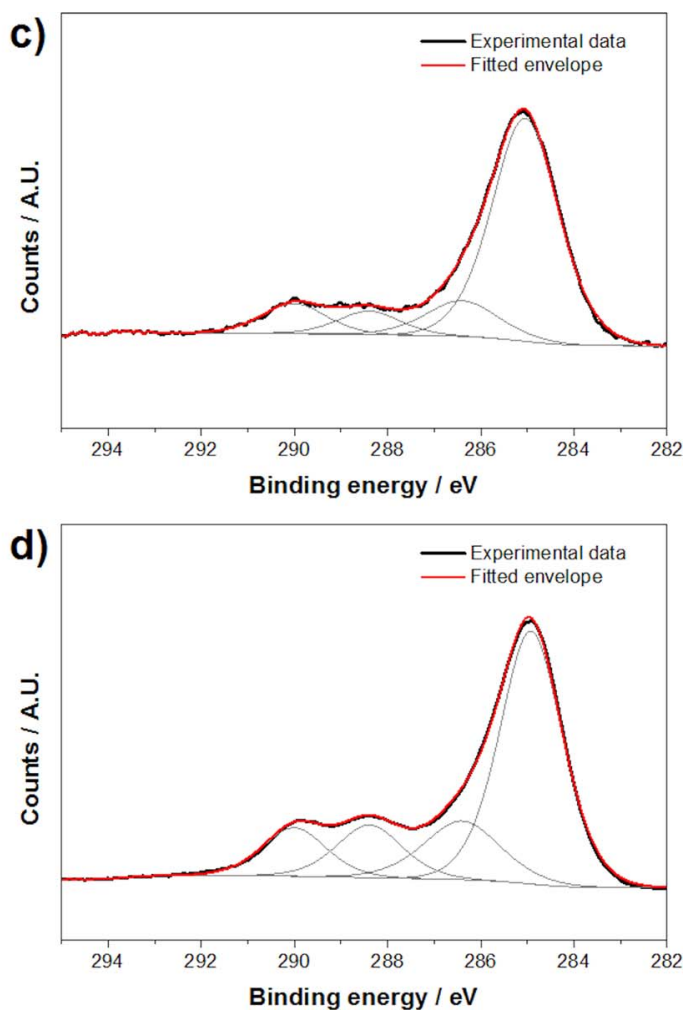

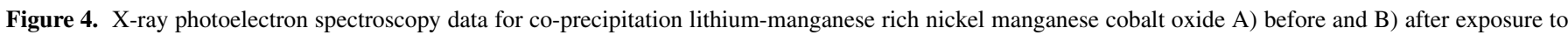
atmosphere and for sol-gel lithium-manganese rich nickel manganese cobalt oxide C) before and D) after exposure to atmosphere. 


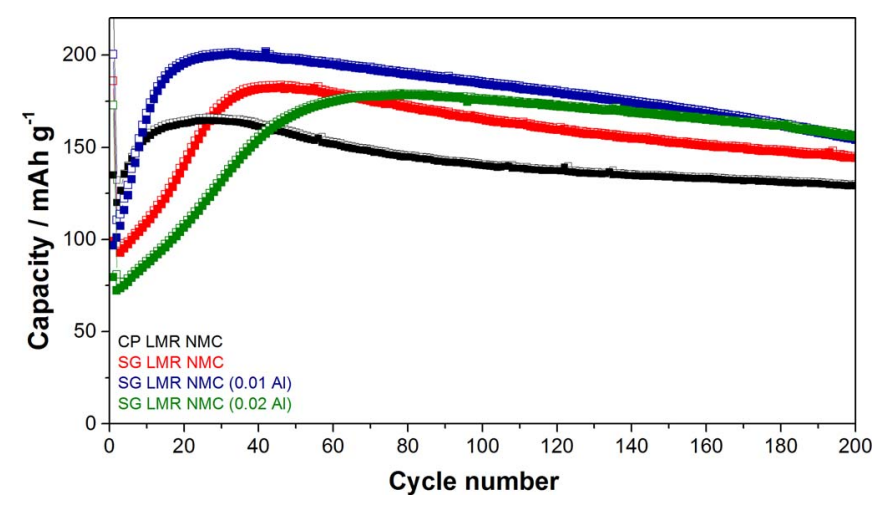

Figure 5. $\square$ Discharge and $\square$ Charge profiles for co-precipitation, sol-gel, sol-gel (0.01 Al doped) and sol-gel (0.02 Al doped) lithium-manganese rich nickel manganese cobalt oxides cycled at high rates.

were performed on both materials A BET analysis of the CP and SG LMR NMC materials gave very similar surface area values (1.79 and $1.59 \mathrm{~m}^{2} \mathrm{~g}^{-1}$ respectively), implying that it is unlikely that the differences in surface reactivity are a result of differences in surface area. Thus it seems reasonable to conclude that the CP LMR NMC particle surface is indeed more reactive than the SG LMR NMC.

Electrochemical characterization. - The materials were cycled at $150 \mathrm{~mA} \mathrm{~g}^{-1}$ LMR NMC between 2.0 and $4.8 \mathrm{~V}$ for 200 cycles. The cyclability plot of the four materials, Figure 5, and the differential capacity plots at cycles 1, 10, 100 and 200 (Figure 6) reveal significant differences in their electrochemical behavior.
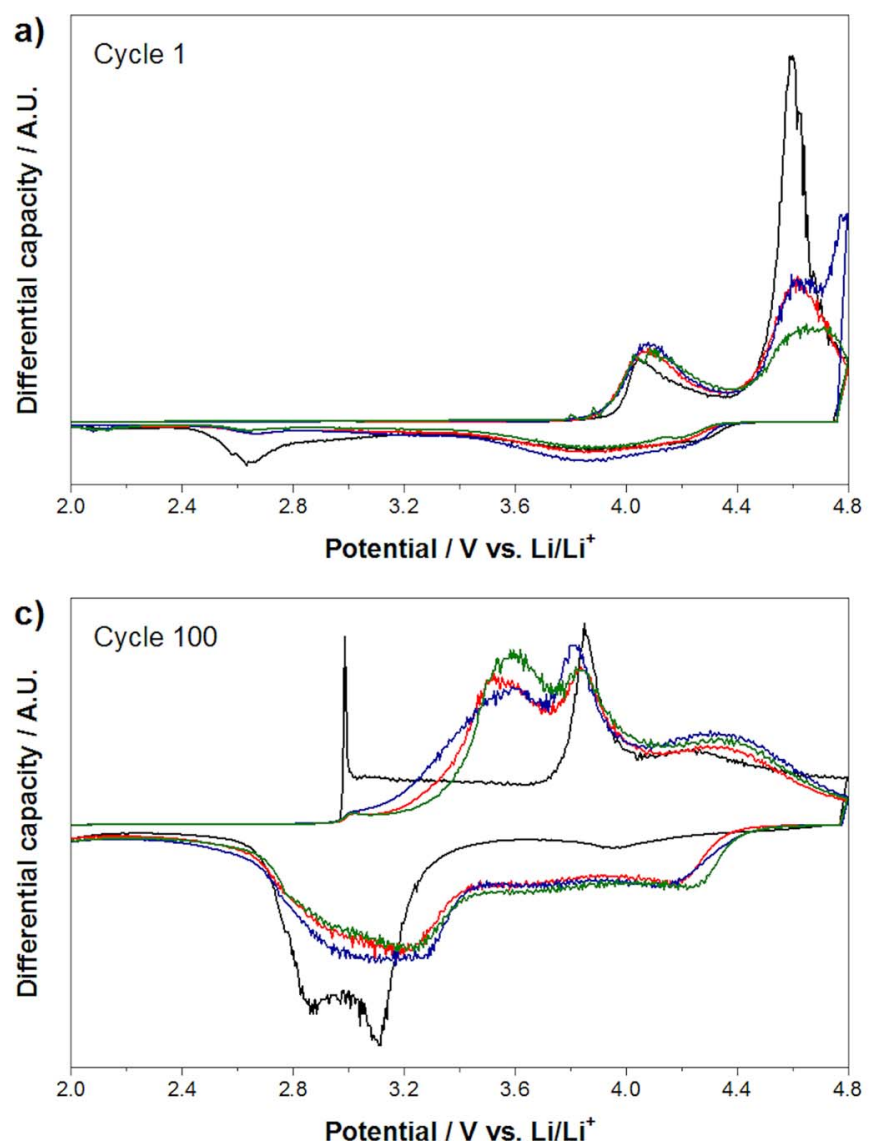

The cycle 1 differential capacity plots shown in Figure $6 a$ are similar, implying that the materials are undergoing the same electrochemical processes, and are in keeping with those of $1^{\text {st }}$ charge/discharge cycles previously reported in the literature. ${ }^{1,2,6,7}$ It may be inferred that all the materials are undergoing a 1 st cycle activation process. In essence, it is believed that the initial charge is a result of lithium deintercalation from the LMR NMC material in the 2.5 to $4.5 \mathrm{~V}$ region (on charge), which is then followed by oxygen and lithium loss, metal ion migration and structural rearrangement in the 4.5 to $4.8 \mathrm{~V}$ region (on charge). Lithium ions are then intercalated back into the cathode during the subsequent discharge. Furthermore, given that the voltage profile of this 1st discharge completely deviates from that of the 1st charge, it is believed that the structural change - proposed to take place during the 1st charge - is permanent. It should be noted that SG LMR NMC $(0.01 \mathrm{Al})$ exhibits an additional peak at $\sim 4.78 \mathrm{~V}$ (on charge) not found in the literature which, whilst currently unidentified, is reproducible for this material and may be linked to the materials comparatively quick activation.

The cycle 10 differential capacity plots shown in Figure $6 \mathrm{~b}$ establish considerable differences between the electrochemical behaviors of the LMR NMC materials. Activity in the $\sim 4.0 \mathrm{~V}$ to $\sim 4.4 \mathrm{~V}$ region is attributable to multiple transition metal species (cobalt and manganese in particular) and processes in both the layered and $\mathrm{Li}_{2} \mathrm{MnO}_{3}$ components. Given that activation and stability of the $\mathrm{Li}_{2} \mathrm{MnO}_{3}$ component is of greatest interest, the electrochemistry undergone in the regions at lower voltages (where the activity of manganese in the $\mathrm{Li}_{2} \mathrm{MnO}_{3}$ component is more easily observed) is the focus of discussion.

The CP LMR NMC shows activity in the $\sim 3.2 \mathrm{~V}$ region (on charge) which is not observable in the other materials. It has previously been suggested that this activity results from $\mathrm{Mn}^{4+/ 3+}$ processes in a "layered-spinel" configuration, i.e. a configuration with both layered
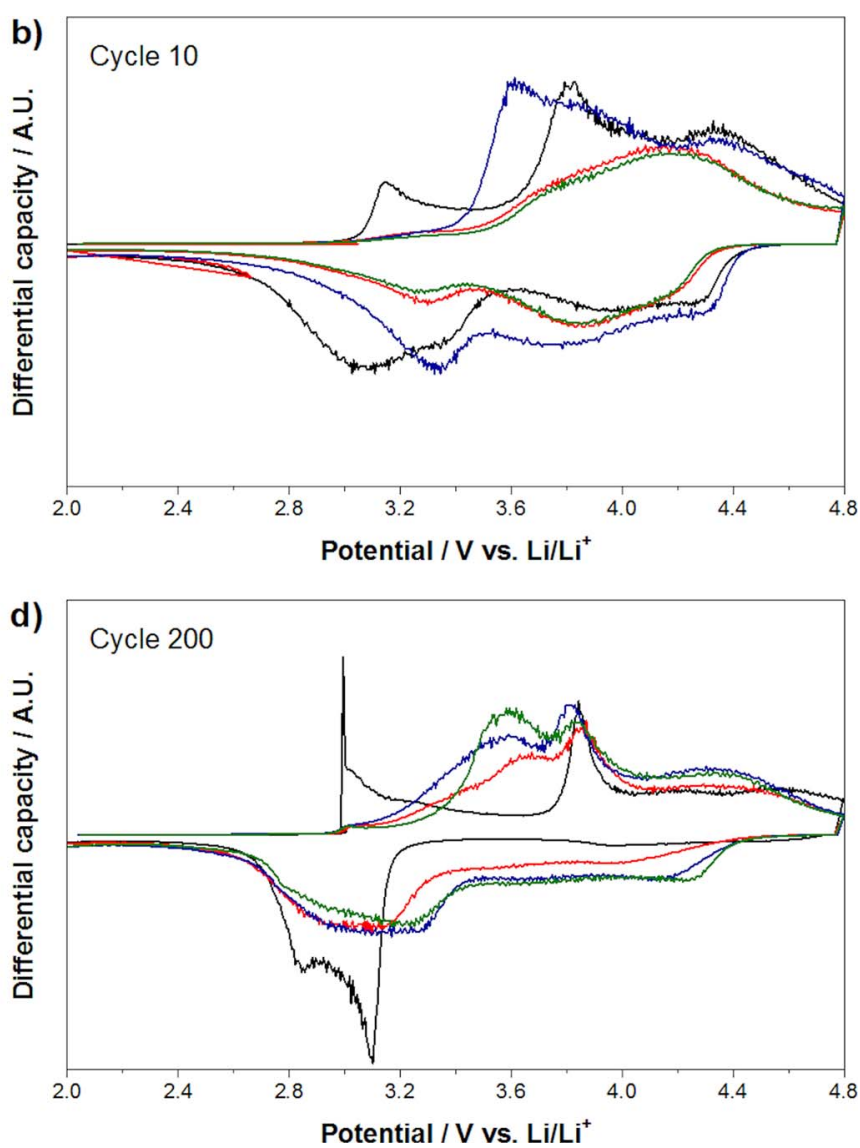

Figure 6. Differential capacity plots for - co-precipitation; - sol-gel; - sol-gel (0.01 Al doped) and - sol-gel (0.02 Al doped) lithium-manganese rich nickel manganese cobalt oxides. 
and spinel components. ${ }^{1,7,8}$ This would imply that, in contrast to the SG materials, the CP material is already undergoing the structural changes leading to voltage fade. This is in keeping with the cyclability data, which shows that at cycle 10 the material is already nearly at its maximum capacity. There is also considerable activity in the $\sim 3.8 \mathrm{~V}$ region (on charge), which has been previously assigned to $\mathrm{Ni}^{4+/ 3+/ 2+}$ processes in the layered component. ${ }^{1,8}$

The SG LMR NMC $(0.01 \mathrm{Al})$ displays considerable activity in $\sim 3.6 \mathrm{~V}$ region (on charge), which is attributable to $\mathrm{Mn}^{4+/ 3+}$ processes in the layered component of lithium-manganese rich mixed metal oxide materials..$^{1,7,8}$ There also appears to be some activity in the $\sim 3.8 \mathrm{~V}$ region (on charge), corresponding to nickel oxidation in the layered component. The activity in these two regions correlates with the substantial increase in capacity that the material exhibits, and that it is already over halfway to reaching its maximum capacity (implying that a large percentage of the activation has already occurred). In contrast to the CP LMR NMC, there is little to no activity in the "layered-spinel" region, implying this material has not yet undergone the degradation leading to voltage fade to any significant degree.

SG LMR NMC and SG LMR NMC (0.02 Al) both have similar differential capacity plots. The overlapping and broad nature of the peaks for these plots makes identifying electrochemical processes difficult, but there appears to be peaks in the $\sim 3.8 \mathrm{~V}$ and $\sim 4.2 \mathrm{~V}$ regions (on charge). Though the electrochemical processes responsible for the broad peak in the $\sim 4.2 \mathrm{~V}$ region are currently unidentified, since they do not appear to be at the voltages previously assigned to nickel or manganese in either the $\mathrm{Li}_{2} \mathrm{MnO}_{3}$ or $\mathrm{LiMO}_{2}$-like regions, ${ }^{1,8}$ we tentatively assign them to a cobalt-center redox process. Whilst the peak at $\sim 3.8 \mathrm{~V}$ may be attributed to $\mathrm{Ni}^{4+/ 3+/ 2+}$ processes, the comparatively low intensity with respect to the CP and SG LMR NMC (0.01 Al) implies that the material is not fully undergoing this process yet which may be a result of the kinetic limitations of lithium extraction from this material at these relatively fast discharge rates.

This hypothesis is supported by the data shown in Figure 7a, a comparison between the SG LMR NMC cell (which was cycled at

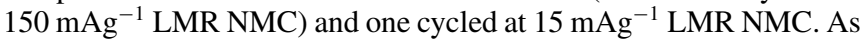
can be seen, the slower rate SG LMR NMC has considerable activity in the 3.8 region (on charge) and an envelope with apparent activity at $\sim 3.6 \mathrm{~V}$ (on charge), suggesting that the speed of activation of both nickel and manganese is dependent on the current rate and thus is related to the kinetics of lithium ion intercalation and deintercalation. This is further supported by a comparison of the cyclability plots for the slow and fast rate SG LMR NMC material, shown in Figure 7b, where the maximum capacity is achieved much sooner at $15 \mathrm{mAg}^{-1}$ LMR NMC than at $150 \mathrm{mAg}^{-1}$ LMR NMC.

The cycle 100 differential capacity plots shown in Figure $6 \mathrm{c}$ demonstrate that the CP LMR NMC is displaying very different behavior from the three SG materials. Since the maximum capacity has been reached for all the SG materials by now (implying their activation stages are complete), their differential capacity plots are now very similar to each other, though there are some observable differences.

The CP LMR NMC shows considerable voltage fade, with a large degree of activity occurring in the region associated with the formation of spinel-like features, with peaks at $\sim 2.9 \mathrm{~V}$ and $\sim 3.1 \mathrm{~V}$ (on discharge) typically assigned to the activity of manganese in spinel and "layeredspinel" type regions respectively. $1,7,8,30$
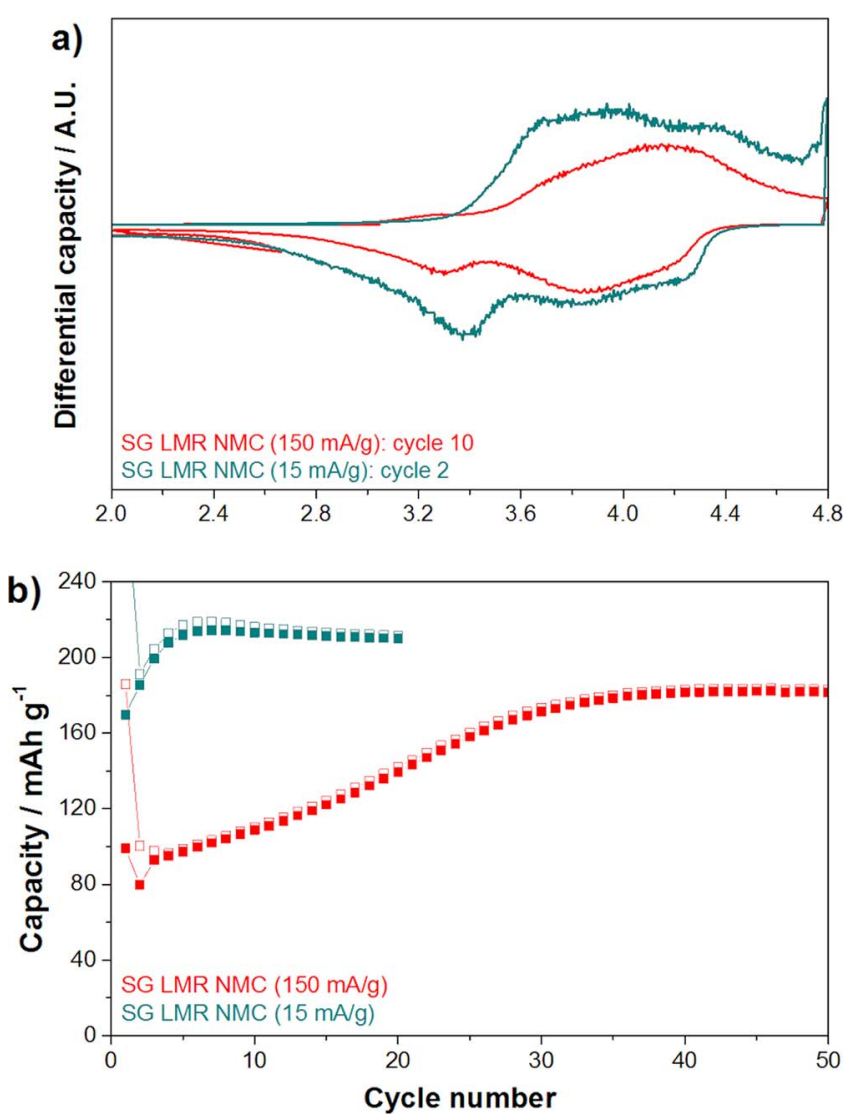

Figure 7. a) Differential capacity plots for slow and fast rate sol-gel lithiummanganese rich nickel manganese cobalt oxides; b) Discharge and $\square$ Charge profiles cycling profiles of slow and fast rate sol-gel lithium-manganese rich nickel manganese cobalt oxides.

The differential capacity plots of the SG LMR NMC, SG LMR NMC $(0.01 \mathrm{Al})$ and SG LMR NMC $(0.02 \mathrm{Al})$ are very similar, with all exhibiting $\mathrm{Mn}^{4+/ 3+}$ processes in the layered component. While these materials also have a little activity in the $\sim 3.2 \mathrm{~V}$ (on charge) "layered-spinel" region, it is considerable less than is observed for the CP LMR NMC material - implying a much greater degree of stability.

The differential capacity plots of the materials after completing 200 cycles, seen in Figure 6d, show a continuation of many of the trends observed at 100 cycles. However, close examination of these in conjunction with the cyclability plot (Figure 5) and the tabulated capacity retention figures (Table III) reveals some interesting differences in the behavior of these materials. In order to ensure that the capacity retention data was not unduly affected by the length of the activation stage, the figures were compared to those calculated by taking a 100 cycle section starting from the maximum capacity, as seen in Table III, which were found to be the approximately the same to 2 significant figures.

Table III. Cycling data for tested Li-Rich compounds.

\begin{tabular}{lcccc} 
Sample & $\begin{array}{c}\text { First cycle } \\
\text { discharge capacity } \\
\left(\mathrm{mAhg}^{-1}\right)\end{array}$ & $\begin{array}{c}\text { Maximum } \\
\text { capacity } \\
\left(\mathrm{mAhg}^{-1}\right)\end{array}$ & $\begin{array}{c}\text { Capacity } \\
\text { retention } \\
\text { (max. to cycle 200) }\end{array}$ & $\begin{array}{c}\text { Capacity } \\
\text { retention } \\
\text { (max. to 100 cycles later) }\end{array}$ \\
\hline CP LMR NMC & 135 & 166 & $82 \%$ & $83 \%$ \\
SG LMR NMC & 100 & 184 & $84 \%$ & $84 \%$ \\
SG LMR NMC (A1 0.01) & 97 & 201 & $88 \%$ & $88 \%$ \\
SG LMR NMC (Al 0.02) & 160 & 180 & $91 \%$ & $91 \%$
\end{tabular}


The CP LMR NMC shows increased voltage fade, resulting from increased activity in the spinel and "layered-spinel" region. Once again both the activity and the increase in activity in this region occur to a greater extent than those observed for the SG materials. Unsurprisingly this exhibits the worst capacity retention of all four materials.

Whilst the SG LMR NMC material exhibits far less activity in the layered and "layered-spinel" regions that the CP LMR NMC, implying better stability, the $\sim 3.6 \mathrm{~V}$ region (on charge) associated with layered manganese processes has still decreased noticeably. Furthermore, there is also a corresponding decrease in the $\sim 3.2 \mathrm{~V}$ to $\sim 3.3 \mathrm{~V}$ region (on discharge) also attributed to layered manganese. ${ }^{1,7}$ It should also be noted that the $\sim 3.2 \mathrm{~V}$ to $\sim 3.3 \mathrm{~V}$ region appears to have decreased significantly when compared to the SG LMR NMC (0.01 Al) and SG LMR NMC (0.02 Al) materials, implying that it has undergone greater structural change and spinel formation. These observations are in keeping with SG LMR NMC capacity retention being superior to $\mathrm{CP}$ LMR NMC, but inferior to those of the SG LMR NMC (0.01 Al) and SG LMR NMC $(0.02 \mathrm{Al})$ materials.

Finally, both the SG LMR NMC (0.01 Al) and the SG LMR NMC $(0.02 \mathrm{Al})$ still display considerable activity in the $\sim 3.6 \mathrm{~V}$ region (on charge) and the $\sim 3.2 \mathrm{~V}$ to $\sim 3.3 \mathrm{~V}$ region (on discharge), implying layered manganese processes are still occurring. However, the SG LMR NMC $(0.02 \mathrm{Al})$ does exhibit more activity in the layered manganese $\sim 3.6 \mathrm{~V}$ region (on charge) and slightly less in the spinel-type $\sim 2.8 \mathrm{~V}$ region (on discharge), implying better stability. This is also in keeping with the relative capacity retentions, with the SG LMR NMC (0.02 Al) exhibiting better cyclability.

The cyclic voltammograms (CVs) for all four materials at cycles 1 and 10 are shown in Figure 8. While the cycle 1 differential capacity plots and CVs (Figures $6 \mathrm{a}$ and 8 a respectively) are in good agreement, from the cycle $1 \mathrm{CVs}$ it can also be seen that there is activity in the $\sim 3.2 \mathrm{~V}$ region (on discharge) which is attributed to the reduction of $\mathrm{Mn}^{4+}$ to $\mathrm{Mn}^{3+}$. This is in keeping with the obtained cycle life data, since the relative activity in this region correlates strongly with the number of activation cycles and electrochemical performance of the four materials. The cycle 10 differential capacity plots and CVs (Figures $6 \mathrm{~b}$ and $8 \mathrm{~b}$ respectively) are also in good agreement, with both demonstrating similar electrochemical processes.

Nyquist plots were produced from electrochemical impedance spectroscopic (EIS) data measured from all four materials prior to cycling and after 200 cycles, as shown in Figure 9a and Figure 9b. There appears to be little difference between the four materials, both prior and post cycling. This is consistent with the Raman data, shown in Figure 9c, which demonstrates no significant change at the electrode surface. Furthermore, the X-ray diffraction (XRD) patterns for CP and SG LMR NMC after 200 cycles (collected using glass capillaries sealed under argon) in Figure 9d show that the CP LMR NMC
(018)/(110) doublet located at $\sim 85^{\circ}$ has converged toward a single reflection, indicative of a trend toward a more spinel-like atomic arrangement, whereas that for the SG LMR NMC is still relatively well separated. Thus, it seems reasonable to conclude that it is structural changes in the bulk which are responsible for the greater portion of voltage fade. Finally, to rule out the effect of the wettability of the porous electrode, a cell was cycled after a $12 \mathrm{hr}$. rest period and was found to exhibit identical cycle life and capacity.

Summary. - The CP LMR NMC rapidly reaches maximum capacity, exhibiting little layered, but considerable "layered-spinel" manganese and layered nickel activity. It has the lowest capacity of the four materials. On cycling it shows considerable activity in the spinel and "layered-spinel" manganese regions, as well as the worst cyclability of all the materials.

The SG LMR NMC undergoes a longer activation process, with increasing intensity of peaks associated with both its layered nickel and its layered manganese processes. It has a good maximum capacity and, together with less activity in the spinel and "layered-spinel" region, it exhibits a good degree of cyclability.

EDX data has shown that, unlike the SG LMR NMC, the CP LMR NMC is particularly nickel deficient compared to the target stoichiometry. Given that it has been demonstrated that this material has a more reactive surface (as seen from the XPS investigation), in particular showing formation of carbonate species to a greater degree, we suggest that the lack of nickel is linked to the charged, reactive nature of the $\mathrm{CP}$ particle surface. Moreover, though the EIS results suggest that the CP LMR NMC is not exhibiting much greater resistance at the surface, there nevertheless appears to be a strong link between the higher surface reactivity and the faster voltage fade. Thus we propose that the reactive surface facilitates the formation of carbonate and carboxyl-like species that leach lithium from the near surface, ${ }^{28,29}$ creating vacancies which expedite the structural changes responsible for the observed voltage fade.

The SG LMR NMC $(0.01 \mathrm{Al})$ material has a very short activation process, with both layered nickel and layered manganese processes visible by cycle 10 . Additionally, it achieves the greatest capacity of all four materials. On cycling the material appears to undergo less structural transformation, and exhibits better cyclability, than the parent SG LMR NMC.

The SG LMR NMC $(0.02 \mathrm{Al})$ material has the longest activation process, and like SG LMR NMC displays slowly increasing intensity of peaks associated with both its layered nickel and its layered manganese processes. The maximum capacity is less than that of the SG LMR NMC $(0.01 \mathrm{Al})$ material, but superior to the parent SG LMR NMC. Moreover, it demonstrates the best cyclability of all four materials.
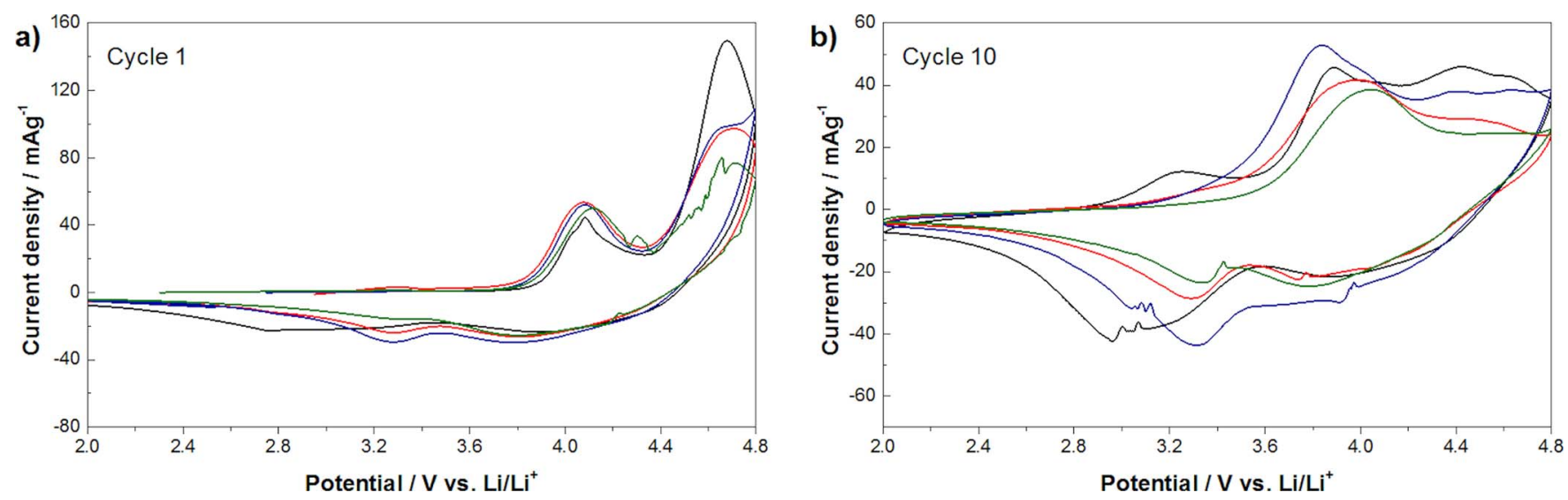

Figure 8. Cyclic voltammograms for - co-precipitation; - sol-gel; - sol-gel (0.01 Al doped) and - sol-gel (0.02 Al doped) lithium-manganese rich nickel manganese cobalt oxides collected at a scan rate of $0.1 \mathrm{mVs}^{-1}$. 

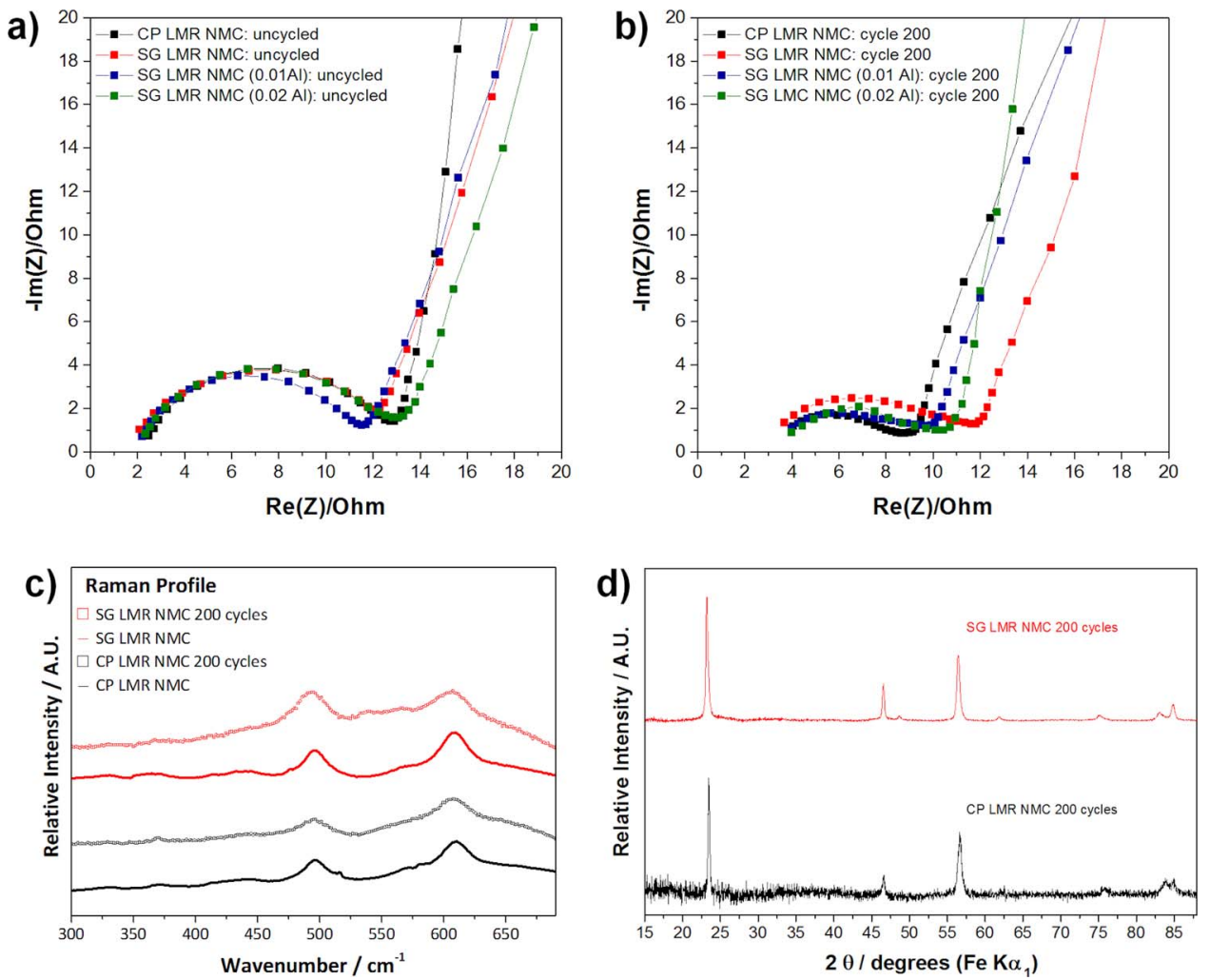

Figure 9. Nyquist plots produced from electrochemical impedance spectroscopic (EIS) data of sol-gel and co-precipitation lithium-manganese rich nickel manganese cobalt oxides measured a) prior to cycling and b) after 200 cycles; c) the Raman spectra before and after cycling; d) XRD patterns for CP and SG LMR NMC after 200 cycles.

Here it may be seen that the degree of aluminum doping is critical to electrochemical performance, and that the SG LMR NMC $(0.02 \mathrm{Al})$ appears to exhibit worse rate capability than SG LMR NMC $(0.01 \mathrm{Al})$. Moreover, that the degree of aluminum doping has such a dramatic effect on the length of the activation step was also unexpected. One explanation is that aluminum doping introduces multiple competing factors. For example, a small degree of aluminum doping may improve lithium ion diffusion and thus expedite the activation of the material, but at higher concentrations reduce diffusion (by decreasing the $c$ lattice parameter) as well as introducing regions of electrochemically inactive aluminum ions that hinder the activation of layered manganese. Another possibility is that the additional peak observed in the cycle 1 charge for SG LMR NMC $(0.01 \mathrm{Al})$ is the result of a process or structural change that is responsible for the layered nickel already being active and the quicker activation of the layered manganese processes. Regardless, further work would be necessary to fully understand the observed trend. Nevertheless, here we have demonstrated that small quantities of aluminum doping can improve rate capability, cyclability and to decrease the voltage fade of a lithium-manganese rich composite with respect to its parent material.

\section{Concluding Remarks}

Detailed studies carried out on co-precipitation and sol-gel synthesized lithium-manganese rich composite materials revealed that the electrochemistry is significantly affected by the choice of synthetic route. This appears to be strongly related to the particles' surface reactivity. Consequently, particle homogeneity and surface stabilization have been demonstrated to be important factors when attempting to minimize voltage fade.

Small degrees of aluminum doping were shown to improve the rate capability and cyclability of a material, as well as decreasing voltage fade. It is apparent that the electrochemistry of an aluminum doped material is highly dependent on the degree of aluminum doping
- with the behavior of the SG $(0.01 \mathrm{Al})$ and SG $(0.02 \mathrm{Al})$ materials differing significantly. It should be noted, however, that both materials also demonstrate improved rate capability, cyclability and decreased voltage fade with respect to the parent SG LMR NMC.

Subsequently, with further careful optimisation, it may be possible to synthesize aluminum doped lithium-manganese rich composites with considerably improved performance compared to their parent material.

\section{Acknowledgments}

We acknowledge the support from the International Research Support Initiative Program, Higher Education Commission, Pakistan; the Science without Borders Program, Ministério da Educação, Coordenação de Aperfeiçoamento de Pessoal de Nível Superior (CAPES) Brazil; and the Engineering and Physical Sciences Research Council (EPRSC) under grant EP/K016954/1. We thank Zoe Taylor for providing BET analyses, and the Nanoinvestigation centre at Liverpool (NiCaL) and discussions with Dr. Vinod Dhanak are also gratefully acknowledged.

\section{References}

1. J. R. Croy, D. Kim, M. Balasubramanian, K. Gallagher, S.-H. Kang, and M. M. Thackeray, J. Electrochem. Soc., 159, A781 (2012).

2. N. Yabuuchi, K. Yoshii, S.-T. Myung, I. Nakai, and S. Komaba, J. Am. Chem. Soc., 133, 4404 (2011).

3. T. Ohzuku, M. Nagayama, K. Tsuji, and K. Ariyoshi, J. Mater. Chem., 21, 10179 (2011).

4. M. Jiang, B. Key, Y. S. Meng, and C. P. Grey, Chem. Mater, 21, 2733 (2009)

5. N. Tran, L. Croguennec, M. Ménétrier, F. Weill, P. Biensan, C. Jordy, and C. Delmas, Chem. Mater, 20, 4815 (2008)

6. A. R. Armstrong, M. Holzapfel, P. Novák, C. S. Johnson, S.-H. Kang, M. M. Thackeray, and P. G. Bruce, J. Am. Chem. Soc., 128, 8694 (2006).

7. C. S. Johnson, N. Li, C. Lefief, J. T. Vaughey, and M. M. Thackeray, Chem. Mater., 20, 6095 (2008)

8. S.-H. Kang, P. Kempgens, S. Greenbaum, A. J. Kropf, K. Amine, and M. M. Thackeray, J. Mater. Chem., 17, 2069 (2007). 
9. K. A. Jarvis, Z. Deng, L. Allard, A. Manthiram, and P. J. Ferreira, Chem. Mater, 23 , 3614 (2011).

10. F. Wu, H. Lu, Y. Su, N. Li, and L. Bao, J. Appl. Electrochem., 40, 783 (2010).

11. L. Croguennec, J. Bains, M. Ménétrier, A. Flambard, E. Bekaert, C. Jordy, P. Biensan, and C. Delmas, J. Electrochem. Soc., 156, A349 (2009).

12. M. M. Thackeray, S.-H. Kang, C. S. Johnson, J. T. Vaughey, R. Benedek, and S. A. Hackney, J. Mater. Chem., 17, 3112 (2007)

13. M. M. Thackeray, S.-H. Kang, C. S. Johnson, J. T. Vaughey, and S. A. Hackney, Electrochem. Commun., 8, 1531 (2006).

14. Y.-S. Hong, Y. J. Park, K. S. Ryu, and S. H. Chang, Solid State Ionics, 176, 1035 (2005).

15. M. M. Thackeray, C. S. Johnson, J. T. Vaughey, N. Li, and S. A. Hackney, J. Mater. Chem., 15, 2257 (2005).

16. Y. J. Park, Y.-S. Hong, X. Wu, M. G. Kim, K. S. Ryu, and S. H. Chang, J. Electrochem. Soc., 151, A720 (2004).

17. C. R. Fell, D. Qian, K. J. Carroll, M. Chi, J. L. Jones, and Y. S. Meng, Chem. Mater. 25, 1621 (2013).

18. J. Zheng, M. Gu, J. Xiao, P. Zuo, C. Wang, and J.-G. Zhang, Nano Lett., 13, 3824 (2013).

19. G. Singh, R. Thomas, A. Kumar, and R. S. Katiya, J. Electrochem. Soc., 159, A410 (2012).

20. L. F. Jiao, M. Zhang, H. T. Yuan, M. Zhao, J. Guo, W. Wang, W. D. Zhou, and Y. M. Wang, J. Power Sources, 167, 178 (2007).
21. B. Song, Z. Liu, M. O. Lai, and L. Lu, Phys. Chem. Chem. Phys., 14, 12875 (2012).

22. A. Dianat, N. Seriani, M. Bobeth, and G. Cuniberti, J. Mater. Chem. A, 1, 9273 (2013).

23. L. Croguennec, J. Bains, J. Bréger, C. Tessier, P. Biensan, S. Levasseur, and C. Delmas, J. Electrochem. Soc., 158, A664 (2011).

24. Z. Li, N. A. Chernova, J. Feng, S. Upreti, F. Omenya, and M. S. Whittingham, $J$. Electrochem. Soc., 159, A116 (2011).

25. C. J. Jafta, K. I. Ozoemena, M. K. Mathe, and W. D. Roos, Electrochim. Acta, 85, 411 (2012).

26. C. S. Johnson, N. Li, C. Lefief, and M. M. Thackeray, Electrochem. Commun., 9, 787 (2007).

27. S. K. Martha, B. Markovsky, J. Grinblat, Y. Gofer, O. Haik, E. Zinigrad, D. Aurbach, T. Drezen, D. Wang, G. Deghenghi, and I. Exnar, J. Electrochem. Soc., 156, A541 (2009).

28. O. Haik, N. Leifer, Z. Samuk-Fromovich, E. Zinigrad, B. Markovsky, L. Larush, Y. Goffer, G. Goobes, and D. Aurbach, J. Electrochem. Soc., 157, A1099 (2010).

29. D. Aurbach, J. Power Sources, 89, 206 (2000).

30. F. Amalraj, M. Talianker, B. Markovsky, L. Burlaka, N. Leifer, G. Goobes, E. M. Erickson, O. Haik, J. Grinblat, E. Zinigrad, D. Aurbach, J. K. Lampert, J.-Y. Shin, M. Schulz-Dobrick, and A. Garsuch, J. Electrochem. Soc., 160, A2220 (2013). 